\title{
8. Abkürzungsverzeichnis
}

\begin{tabular}{|c|c|c|}
\hline ADMV & $=$ & Allgemeiner Deutscher Musikverein \\
\hline BefrG & $=$ & $\begin{array}{l}\text { Gesetz zur Befreiung von } \\
\text { Nationalsozialismus und Militarismus }\end{array}$ \\
\hline Briefausgabe Adamy & $=$ & $\begin{array}{l}\text { Adamy, Bernhard (Hrsg.) } \\
\text { „Hans Pfitzner Briefe“, Tutzing } 1991\end{array}$ \\
\hline Gesammelte Schriften & $=$ & $\begin{array}{l}\text { Hans Pfitzner "Gesammelte Schriften“" } \\
\text { in vier Bänden }\end{array}$ \\
\hline Gestapo & $=$ & Geheime Staatspolizei \\
\hline GMD & $=$ & Generalmusikdirektor \\
\hline HS & $=$ & Handschriftensammlung \\
\hline $\mathrm{KdF}$ & $=$ & Organisation „Kraft.durch Freude“ \\
\hline $\mathrm{KfdK}$ & $=$ & Kampfbund für deutsche Kultur \\
\hline MHPG & $=$ & Mitteilungen der Hans Pfitzner-Gesellscha \\
\hline NSKG & $=$ & $\begin{array}{l}\text { Nationalsozialistische Kulturgemeinde, } \\
\text { Folgeorganisation des KfdK }\end{array}$ \\
\hline N. N. & $=$ & ohne Autor \\
\hline ÖN Wien & $=$ & Österreichische Nationalbibliothek Wien \\
\hline o. M. & $=$ & ohne Monat \\
\hline o. O. & $=$ & ohne Ort \\
\hline o. op. & $=$ & ohne Opuszahl \\
\hline o. Sign. & $=$ & ohne Signatur \\
\hline o. T. & $=$ & ohne Titel \\
\hline o. P. & $=$ & ohne Paginierung \\
\hline op. & $=$ & opus \\
\hline o. V. & $=$ & ohne Vornamensnennung \\
\hline Pg. & $=$ & Parteigenosse der NSDAP \\
\hline Propagandaministerium & $=$ & $\begin{array}{l}\text { Reichsministerium für Volksaufklärung und } \\
\text { Propaganda }\end{array}$ \\
\hline resp. & $=$ & respektive \\
\hline RKK & $=$ & Reichskulturkammer \\
\hline RMK & $=$ & Reichsmusikkammer \\
\hline RTK & $=$ & Reichstheaterkammer \\
\hline STAGMA & $=$ & $\begin{array}{l}\text { Staatlich genehmigte Gesellschaft zur } \\
\text { Verwertung musikalischer Urheberrechte, } \\
\text { heutige GEMA }\end{array}$ \\
\hline$[\ldots]$ & $=$ & $\begin{array}{l}\text { In eckige Klammern gesetzte Einschübe } \\
\text { kennzeichnen grundsätzlich Anmerkungen } \\
\text { oder Ergänzungen der Verfasserin. }\end{array}$ \\
\hline
\end{tabular}

